\title{
JOVENS PICHADORES: PERFIL PSICOSSOCIAL, IDENTIDADE E MOTIVAÇÃO
}

\section{Alex de Toledo Ceará Paulo Dalgalarrondo}

Resumo: Este estudo investigou o perfil psicossocial dos adolescentes envolvidos com a prática da pichação urbana.Trata-se de uma subcultura vinculada ao movimento hip hop, presente nas médias e grandes cidades brasileiras. Teve como objetivo descrever os processos identitários e motivacionais desses adolescentes. Dessa forma, 32 sujeitos responderam a um inventário que abordou aspectos psicológicos e socioculturais da pichação. Os jovens pichadores eram todos do gênero masculino, de idade média 17,2 $\pm 2,6$ anos e moradores da periferia de grandes cidades. As entrevistas revelaram que a pichação relaciona-se a marcantes processos identitários para seus autores, assim como indicaram a forma com que se relacionam com seus pares e líderes e como se relacionam com a sociedade geral e a lei. Conclusão: os jovens envolvidos com a pichação lançam mão dessa prática como forma de demarcar suas identidades e confrontar a sociedade. A pichação foi analisada segundo os conceitos de Erik Erikson referentes à crise de identidade na adolescência. Observou-se a implicação das ideologias de marketing da sociedade geral e dominante, articuladas com o processo da pichação.

Palavras-chave: Adolescentes. Identidade. Grafite (arte).

\section{Pichação e Grafitagem: Aproximações e Distanciamentos}

O fenômeno da pichação, definido como a prática transgressora de produzir escritos cifrados nas paredes de prédios e locais públicos das médias e grandes cidades, se alastra vertiginosamente no contexto urbano brasileiro atual. $\mathrm{O}$ sentido 


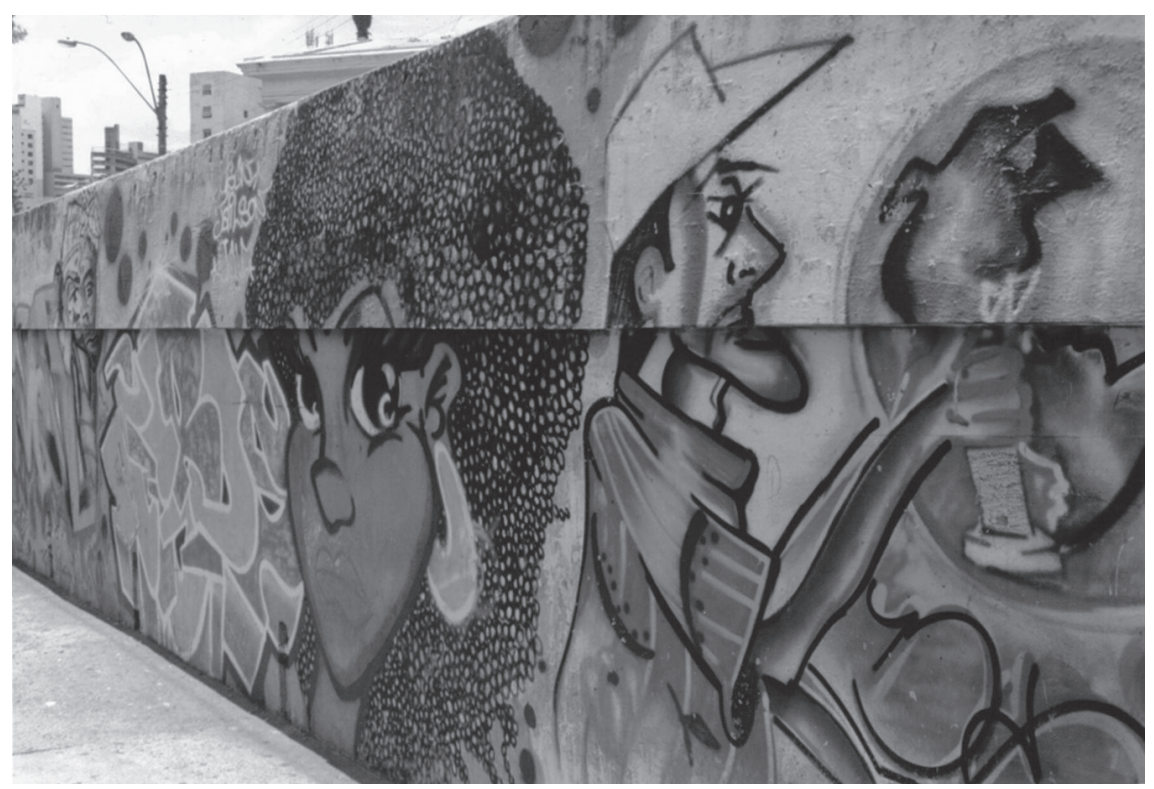

Foto I. Grafite com elementos do movimento Hip hop.

psicossocial do fenômeno articula processos identitários de seus autores, geralmente organizados em grupos de adolescentes, com matizes relacionados à transgressão, tanto em sua origem como nos seus desdobramentos (Silveira, 1991).

A pichação, nas sociedades contemporâneas, relaciona-se ao desenvolvimento da grafitagem. Essa, muitas vezes, tem se confundido com a pichação, mas historicamente antecede a ela (Lara, 1996). Segundo Lara (1996), os grafites surgem e intensificam-se nos movimentos rebeldes dos anos 60, principalmente na França. Ganharam forte conotação contestadora de caráter político e cultural nessa época, caracterizada pelas frases e termos de protesto. No inicio dos anos 70, essa prática ganha nos Estados Unidos forma e significados diferentes. A grafitagem passa, nesse contexto, a ser assimilada por grupos pertencentes aos guetos de jovens afro-americanos e hispânicos.

Assimilada por populações jovens marginalizadas das grandes metrópoles dos Estados Unidos, a grafitagem irá incorporar-se a movimentos sociais e culturais ali existentes, principalmente com a cultura negra de rua, a chamada cultura hip hop, que surgira nos anos 60 . A pichação e a grafitagem, hoje, no Brasil, associa-se intimamente à cultura hip hop. 




Foto 2. Pichação com a marca "Sinicos" da grife "Os + Imundos".

Segundo Magro (2002), o hip hop é um movimento juvenil constituído por uma linguagem musical, o rap (rhythm and poetry) dos "rappers" e DJ's, pela Street Dance (o break) e a arte plástica (o graffiti e a pichação), tudo isso num contexto de identificação com a etnicidade negra. Esse último elemento da cultura hip hop, a grafitagem, compreende grande parte da pichação, embora se diferencie desta em suas formas gráficas. A grafitagem é freqüentemente representada em figuras e desenhos coloridos, e a pichação em escritos cifrados, quase que na sua totalidade. A pichação também se distingue pela organização dos grupos que a praticam e pela intensidade da conotação transgressora que possui. Da cultura hip hop, é o elemento mais claramente transgressor.

No Brasil, introduziu-se a prática dos escritos de parede nas comunidades periféricas em cidades médias e grandes a partir dos anos 80 . Com 
Alex Vallouri, um artista plástico, ganhou uma forma gráfica que marcará a grafitagem nacional, diferenciando-se da pichação atribuída apenas aos escritos e letras codificadas (Silveira,1991).

A pichação tem adquirido características próprias, marcadas tanto pela linguagem cifrada como pela organização grupal de seus autores, quase todos adolescentes. O caráter transgressor e identitário são também aspectos marcantes e distintivos dessa prática social.

Há poucos estudos em nosso meio sobre perfil psicossocial, identidade, motivações e conflitos dos jovens que praticam a pichação e se envolvem em atos análogos de transgressão. Com o objetivo de investigar esses jovens numa perspectiva inicialmente exploratória, realizou-se a presente pesquisa.

\section{Abordando os sujeitos e seu universo urbano}

No período de novembro de 2004 a maio de 2005 foram entrevistados 32 adolescentes, de cidades pertencentes à região metropolitana de Campinas-SP.Dos 32 adolescentes, 19 foram entrevistados ao participarem de um programa de medida socioeducativa de liberdade assistida a adolescentes infratores, e 13 foram convidados à entrevista através de seus colegas. Os sujeitos situavam-se na faixa etária de 13 a 23 anos, residiam em zonas periféricas de tais cidades e praticavam regularmente a pichação.

Foi elaborado um inventário baseado na literatura e em quatro entrevistas-piloto previamente realizadas. Esse inventário foi constituído de 43 questões, sendo 13 de ordem sociodemográfica e 30 que abordavam aspectos significativos do universo da pichação, suas implicações identitárias e seus significados psicológicos e socioculturais.

Tratou-se de um estudo qualitativo que utilizou entrevistas semiestruturadas. Os 32 adolescentes pichadores foram entrevistados em encontros individuais de cerca de 40 minutos. As respostas obtidas foram separadas em questões fechadas e questões abertas, relativas à prática da pichação segundo seus autores.

Foram feitas tabelas com estatística descritiva das variáveis quantitativas. As respostas obtidas pelos depoimentos dos jovens foram agrupadas segundo blocos temáticos e conteúdos significativos que se repetiram ao longo das entrevistas. Para a análise do material, foram utilizados procedimentos da metodologia qualitativa em pesquisa em saúde, sobretudo a "análise de conteúdo." As técnicas de análise foram principalmente a "análise de expressão" e a "análise temática", segundo descrito por Minayo (2004). 


\section{Perfil dos adolescentes pichadores}

O perfil sociodemográfico da amostra estudada $(n=32)$ revelou que a idade média foi de 17,2 $\pm 2,6$ anos (13-23) anos.

Em relação à escolaridade, 19 (59,3\%) tinham nível fundamental incompleto, 10 (31,3\%) tinham nível médio incompleto e três $(9,4 \%)$ tinham completado ensino fundamental. Em relação a estarem estudando ou não, $19(59,3 \%)$ ainda estudavam e 13 (40,6\%) tinham interrompido os estudos, sendo que todos que interromperam os estudos o fizeram no nível fundamental. Os motivos alegados para a interrupção dos estudos foram: ter cometido algum ato infracional e/ou ter sido detido (6: 18,7\%), necessidade de trabalhar (3:9,3\%) e, finalmente, não apresentaram motivos (3:9,3\%).

A respeito da situação conjugal dos pais, $20(62,5 \%)$ tinham seus pais casados, 7 (21,9\%), separados, e 5 (15,6\%) tinham pais ou mães falecidos.

Em relação à religiosidade dos adolescentes, 12 (37,5\%) afirmaramse católicos, 19 (59,3\%) evangélicos, 5 (15,6\%) não ter religião e 1 (3,1\%) afirmou-se testemunha de Jeová. Já em relação às mães, 16 (50\%) afirmaram-se católicas, 13 (40,6\%) evangélicas, 2 (6,2\%) não ter religião e $1(3,1 \%)$ afirmou-se testemunha de Jeová. Dos pais, 17 (53,1\%) afirmaram-se católi$\cos , 7(21,8 \%)$ evangélicos e $1(3,1 \%)$ não tinha religião.

Em relação ao histórico das infrações cometidas, 12 (37,5\%) afirmaram não ter cometido qualquer infração, $9(28,1 \%)$ praticaram assalto à mão armada, 5 (15,6\%) praticaram roubo ou furto, 4 (12,5\%) praticaram vandalismo, 1 (3,1\%) praticou estupro e $1(3,1 \%)$ praticou agressão física grave. Finalmente, em relação ao tempo e forma de início da pichação, 16 (50\%) iniciaram há mais de três anos, 10 (31\%) entre um e dois anos e seis (19\%) há menos de um ano. A motivação para começar a pichar foi, em 29 (91\%), "por envolvimento com um grupo de pichadores", em 2 (6\%), por "interesse pessoal" e um (3\%) não citou o motivo.

Nos quadros 1 e 2 são apresentadas as características desse grupo em relação a aspectos das identidades e significados das pichações.

Quadro 1. Identidades e significados de "pichar"

\begin{tabular}{|l|c|}
\hline \multicolumn{2}{|c|}{ Autodescrição do "ser pichador" (a que relacionam o"ser pichador") } \\
\hline Necessidade de expressar conteúdos internos & $12(37,5 \%)$ \\
\hline Desejo de se tornar conhecido & $7(21,8 \%)$ \\
\hline Prazer de se expor ao risco/perigo & $7(21,8 \%)$ \\
\hline Ser pichador como reação à marginalização & $2(6,2 \%)$ \\
\hline Uma prática similar ao trabalho & $2(6,2 \%)$ \\
\hline Não deram respostas sobre a questão & $2(6,2 \%)$ \\
\hline
\end{tabular}




\begin{tabular}{|c|c|}
\hline \multicolumn{2}{|l|}{ Descrição do que é "pichar" } \\
\hline Necessidade de expressar emoções/pensamentos & $16(50 \%)$ \\
\hline Procura em se tornar conhecido, ter ibope e vivenciar risco/perigo & $8(25 \%)$ \\
\hline Procura em se tornar conhecido, ter ibope & $3(9,3 \%)$ \\
\hline Não deram respostas nesse item & $3(9,3 \%)$ \\
\hline Necessidade de obter auto-controle com essa prática & $2(6,2 \%)$ \\
\hline \multicolumn{2}{|l|}{ Motivos na escolha dos locais pichados } \\
\hline Importância da obtenção de "ibope" na escolha de lugares & $10(31,3)$ \\
\hline Importância de picharem lugares altos & $7(21,8 \%)$ \\
\hline Importância de se pichar em todos os lugares & $4(12,5 \%)$ \\
\hline Importância em obter permissão do proprietário do imóvel para pichar & $2(6,2 \%)$ \\
\hline \multicolumn{2}{|l|}{ O que é pichado por eles } \\
\hline Picham "marcas", palavras únicas que denominam um dado grupo & $30(90,6 \%)$ \\
\hline Não mencionaram o que picham & $1(3,1 \%)$ \\
\hline Picha diversas formas de desenho & $1(3,1 \%)$ \\
\hline \multicolumn{2}{|l|}{ A pichação mais significativa para eles } \\
\hline Referem risco relacionado a uma autoridade policial ou civil & $18(56,2 \%)$ \\
\hline Referem risco/perigo de forma geral & $5(15,6 \%)$ \\
\hline Fazem alusão à "aventura" & $3(9,3 \%)$ \\
\hline Fala sobre o "ibope" pelo ato cometido & $1(3,1 \%)$ \\
\hline
\end{tabular}

\section{Quadro 2. Identidade étnica, composição grupal e percepção da sociedade}

\begin{tabular}{|l|l|}
\hline \multicolumn{2}{|c|}{ Grupo étnico em que os jovens incluíam-se } \\
\hline Percebidos como brancos pelo entrevistador e consideravam-se brancos & $10(31,2 \%)$ \\
\hline Percebidos como mulatos pelo entrevistador e consideravam-se negros & $7(21,8 \%)$ \\
\hline Percebidos como brancos pelo entrevistador e consideravam-se negros & $6(18,7 \%)$ \\
\hline Percebidos como mulatos pelo entrevistador e consideravam-se mulatos & $3(9,3 \%)$ \\
\hline Percebido como mulato pelo entrevistador e considerava-se branco & $1(3,1 \%)$ \\
\hline
\end{tabular}




\begin{tabular}{|c|c|}
\hline \multicolumn{2}{|l|}{ Os que picham sozinhos ou em grupo } \\
\hline Picham em grupo & $23(71,8 \%)$ \\
\hline Picham em grupo e sozinhos & $8(25 \%)$ \\
\hline Picha sozinho & $1(3,1 \%)$ \\
\hline \multicolumn{2}{|c|}{ Sobre a liderança do grupo ("cabeças" de suas "marcas") } \\
\hline Grupos que tinham líderes e "alianças" com grupos maiores ("grifes") & $23(71,8 \%)$ \\
\hline Grupos que não tinham líderes e "alianças" com grupos maiores ("grifes") & $8(25 \%)$ \\
\hline \multicolumn{2}{|l|}{ Como percebem as leis } \\
\hline As leis podem ou não ter sentido, relativizam & $25(78,1 \%)$ \\
\hline Necessidade de obedecê-las, embora não o façam & $7(21,9 \%)$ \\
\hline \multicolumn{2}{|l|}{ Como julgam que a sociedade os percebe } \\
\hline Citam que a sociedade os percebe como vândalos e marginais & $32(100 \%)$ \\
\hline \multicolumn{2}{|c|}{ Como percebem a polícia e julgam que a polícia os percebe } \\
\hline Pensam que a polícia os percebe como marginais e vagabundos & $32(100 \%)$ \\
\hline Vêem a polícia de forma negativa, violenta e corrupta & $25(78,1 \%)$ \\
\hline Vêem a polícia como aqueles que fazem o seu trabalho & $7(21,8 \%)$ \\
\hline
\end{tabular}

\section{A Pichação e seus Autores: uma Análise Psicossocial}

\section{A população estudada}

O presente estudo investigou uma população jovem, de baixo poder aquisitivo e com um nível de escolaridade também abaixo do que era esperado para a faixa etária. Um número elevado (13:41\%) havia interrompido seus estudos. Das interrupções, todas foram realizadas no ensino fundamental, indicando um afastamento precoce da escola, seja por condutas delinqüentes ou por limitações socioeconômicas.

São adolescentes moradores de zonas periféricas de grandes e médios centros urbanos, núcleos comerciais e industriais. Vivem numa discrepante situação socioeconômica, evidenciando-se um marcante contraste entre os recursos tecnológicos/mercadológicos de suas cidades (região de indústrias de média e alta tecnologia) e suas condições concretas de 
vida. Esse contraste entre os papéis sociais ideologicamente valorizados e as reais possibilidades em alcançá-los demarca um contexto que pode intensificar uma determinada forma de crise de identidade e de relação com o mundo adulto (Erikson, 1972).

Sobre a religiosidade desses jovens, notou-se que a maioria deles se afirmou como evangélico, e em menor número como católico, o mesmo se repetindo, embora numa proporção menor, em relação às mães. Considerando que as religiões evangélicas expressam, de modo geral, preceitos e regras de conduta claramente estritas e exigem um comportamento moralmente correto, tais exigências não parecem inibir ou restringir as atitudes transgressoras desses jovens. Também não moldam suas percepções sobre seus comportamentos, pois, em sua totalidade, os adolescentes viram na prática da pichação uma manifestação legítima, ainda que proscrita. Além disso, muitos pichadores já haviam cometido algum ato infracional, em sua maioria, grave.

Possivelmente, a auto-expressão no grupo e na comunidade, associada à necessidade de possuir visibilidade social e construir uma identidade transgressora, mas, ao mesmo tempo, notável, foram mais fortes e determinantes do que as proibições religiosas e morais. Outra possibilidade explicativa para essa alta adesão às igrejas evangélicas é que "compartimentalizem" os dois universos: o da pichação, o mundo dos "moleques", do "piche", do "ibope" e o mundo da igreja, dos cultos e prescrição dos pastores. O fato deles apresentarem um percentual (19: 59\%) de afiliação a igrejas evangélicas ainda maior que suas mães (13:41\%) é intrigante e possivelmente implique buscas por outras formas de socialização em tais denominações.

\section{Dimensão grupal da pichação}

Notou-se que a pichação é uma prática experenciada grupalmente (23,72\%, o faziam em grupo), acrescentando-se a esse dado a constatação de que 29 (91\%) dos jovens iniciaram tal prática através de um envolvimento ou convite grupal. Esses grupos organizam-se, muitas vezes, em torno de um líder, denominado "cabeça",embora isso não seja absoluto ou obrigatório, pois foram verificados, numa minoria, grupos sem líderes e pichações realizadas por sujeitos individuais. De modo geral, os líderes são os criadores de uma pichação específica, original, chamada "marca" (por exemplo, "os cínicos," "agonia", "os sombras," "senha", "os réus", "agora"). Tal "marca" é caracterizada por ser uma palavra única, que identifica um dado grupo. Após essa criação, alguns outros adolescentes são convidados a participar da propagação dessa "marca", do processo de "levantar"a mesma. A grande maioria dos sujeitos nesse estudo pichava, sobretudo,"marcas".Elas são, na maioria das vezes, cifradas, ilegíveis para as pessoas alheias ao grupo ou à 
subcultura, apenas reconhecendo-as os que a ela pertencem.

A maior parte dos pichadores pertencentes a subgrupos também estava vinculada a grupos maiores, chamados de "grifes" (por exemplo, "os + imundos","DK-dead Kennedy","os RGS-registrados","onix"). Essas "grifes" possuem outros líderes, que através dessa vinculação, chamada de "aliança", devem pichar, além de suas "marcas", as "marcas" das "grifes" numa mesma pichação. Dessa forma, com tais alianças, os jovens conseguem, caso se alinhem a uma "grife" forte, um potencial de maior "eficiência identitária" e competitividade, pois, ao participarem de "marcas" e "grifes" mais divulgadas e conhecidas, tornam-se, eles mesmos, mais "visíveis".

Para a pactuação e realização de alianças e trocas de experiências, os jovens encontram-se em locais determinados das cidades, os "points", onde trocam escritos (feitos em folhas de papel), colecionando as "marcas" uns dos outros, estabelecendo-se um processo de intensa interação e negociação entre seus participantes, criando-se, assim, uma comunidade capaz de estabelecer suas próprias metas e papéis a serem construídos.

\section{Motivação para a pichação}

Notou-se nesse estudo que as motivações para a escolha dos locais pichados indica a valorização dos prédios mais altos, os edifícios públicos (que eventualmente saem nos jornais quando pichados), trens etc. Eles proporcionam o que esses jovens chamam de "ibope", ou seja, tornar-se conhecido, visível, através da pichação.

As narrativas abaixo expressam tais aspectos:

Pra mim é aquele que, se tem um lugar exato, tem um ponto mais alto, ele procura isso pra pegar mais ibope, pra que todo mundo possa ver. Tem vários que fazem, daí aquele que faz outra grife fala e vê "aqueles moleques tão fazendo mesmo". Tem aquele que "quebra o seu" (picha mais alto). Na verdade tem que ter espaço, se não já era, você quebra o cara que fez antes.

É diversão, adrenalina, várias coisas... é pra se divertir mesmo, diversão e ganhar ibope, pra ser conhecido e ter o nome lá no alto. Na época isso era importante, agora não tem mais sentido. Já faz 2 anos que eu parei. Tomei muito banho de tinta de polícia. Daí eu caí na real e não quis mais. Todo mundo que era da mesma marca foi parando e eu parei também.

É um cara que deixa sua marca, ou algo parecido. No mundo dos pichadores é importante isso. É aquele que tem mais ibope. É fazer mais picho do que o outro. Pegar uns picos é ter mais picho. 
Cabe notar que a forma como procuram locais para inscreverem suas "marcas" é algo análogo à forma como o sistema de comunicação e marketing da sociedade em geral estabelece visibilidade. Curiosamente, através do processo impessoal e massificante do marketing, a sociedade dominante cria espaços anônimos e desterritorializados; os sujeitos urbanos, os jovens aqui estudados, em certo sentido, "reterritorizalizam-se", através da pichação.

Hall (2003) cita que as sociedades ocidentais pós-modernas são orientadas pelo sistema globalizante de mercado, caracterizado pela total fluidez de mercadorias e marcas. Elas carregam em si as referências culturais concernentes à sua origem, promovendo uma nova e marcante descentralização da identidade das pessoas na pós-modernidade. Essa descentralização é agora marcada pelo contato contínuo com novas culturas das mais diversas regiões do mundo, tendo como característica básica as regras liberais de comércio, comércio esse alicerçado em avançadas formas de publicidade e marketing. Paradoxalmente, essas ideologias de mercado estão também presentes na busca e na formação das identidades dos adolescentes marginalizados nas grandes cidades, e em suas organizações grupais, através de seus líderes, "marcas" e "grifes", que se manifestam em práticas da cultura urbana marginal, como a pichação.

A pichação configura-se, assim, como uma atividade que invade os espaços das metrópoles, num processo que Silveira (1991) denomina "deriva pelos interstícios sociais."Formam-se territórios itinerantes que podem ser compreendidos como uma manifestação do sistema de comunicação presente nas sociedades complexas, marcadas pela fluidez e multiplicidade. Nesse processo de multiplicidade e pulverização das mensagens visuais, vê-se, como objetivo desses jovens, pichar a mesma inscrição na maior quantidade possível de locais públicos, de alta circulação de pessoas. $\mathrm{Na}$ maioria das vezes buscam locais estrategicamente situados, no intuito de marcar maior visibilidade e importância no cenário urbano.

Sendo a busca de visibilidade social (o "ibope") o primordial para tais jovens, esta dá-se competitivamente entre os grupos na execução dos escritos que se espalham pelas cidades. Os momentos de maior tensão ocorrem quando um grupo picha por cima dos escritos de outro ("atropelando").

Eu criava, era isso aí, tem grupos que disputam quem picha mais. O que picha mais alto ganha uma estrela, mas para mim não tinha essa competição. Eu vi umas treta destes grupos aí no Iguatemi em Campinas, uns caras mataram o outro por causa de competição, de atropelar, por causa disso.

A rivalidade se expressa exemplarmente quando um grupo consegue pichar mais alto do que outro grupo no mesmo local.É o que denominam "quebrar" a pichação do outro. Entretanto as disputas por pichar mais 
alto é algo como que normatizado entre os pichadores e talvez por isso implique em menos violência.

\section{Identidade e pichação}

Essas características de organização e funcionamento intra e inter grupal revelam superidentificações com facções e movimentos de pares e consolidam uma certa forma de identidade psicossocial (Erikson, 1972). Experimenta-se, assim, no grupo de pichadores, um reconhecimento articulado a um status, um posicionamento no campo social, que não é dado pela sociedade mais ampla, mas, no grupo, o é. Assim, o"ibope"e a busca de locais de grande circulação, para os pichadores, tornam-se cruciais.

Para Erikson (1972), o sentimento de pertencimento ao grupo é um aspecto essencial da experiência e constituição de uma identidade adolescente. Intolerância (aos rivais) e pertencimento (no seu grupo) são sentimentos fundamentais. A observância das relações de lealdade, competitividade, desempenho, condizentes com a necessidade de diferenciação desses jovens no seu mundo, articula-se a um processo de incorporação de características e comportamentos orientados por ideologias do próprio mundo adulto dominante.

Os relatos sobre o significado de ser pichador, bem como aqueles da prática do pichar, revelam a necessidade de expressão da subjetividade, de exposição a riscos em que se obtêm reações emocionais intensas e a notoriedade social:

Era uma quinta-feira, trombei três colegas. Fomos pichar. No primeiro muro, começando a primeira letra os "home" colô. Saímos comendo pelo canto do muro, se jogamos no chão, os "home" parou na esquina bateu geral em dois moleques e começou a procurar algo, passou o farolete por uma de nossas cabeças, que estávamos deitados; o coração foi a mil de medo de ser pego no flagra da pichação. Por sorte não nos viram e seguiram em frente. Continuamos a pichar.

Eu fui pichar uma escola de deficientes. Eu estava bêbado, aí subi pelo pára-raio aí pichei tudo. Fiz todo o negócio, aí quando desci a polícia já estava me esperando lá embaixo. Doeu um pouco, mais foi legal.

Foi na Av. Campos Sales, na escola Catedral. Nóis tava em 3 moleques em cima, e a polícia enquadrou os moleques que eram 4 embaixo, enquadrou eles e dispensou. Daí um taxista viu a gente e chamou a polícia no celular. Nós vimos ele e saímos correndo pro centro de convivência, e a polícia não pegou nenhum dos 3. Foi a mais divertida, fora os banhos de tinta, foi o que deu mais adrenalina, foi isso. 
As vezes que eu tomei banho de tinta eu nem comecei a pichar e a polícia me pegou. Encheu de tinta o tênis e o boné, e mandou vestir.

Teve uma mão que eu e o Ski, o finado Bob, fomos catar um prédio que já fazia três dias que queríamos catar e não surgia a oportunidade. Então um dia invadimos o bagulho junto com os moradores, mas eles não sabiam o que íamos fazer. Aía gente entrou e o guarda ainda cumprimentou a gente pensando que estávamos todos juntos, aí chegando lá em cima tivemos que arrombar a clara bóia, não era tão alto, ficamos um de costa pro outro, levantei o Ski, e ele chutou o bagulho até abrir. Aí rebentamos e descemos na maior cara de pau, todos imundos.

Silêncio... Foi esses dias agora. Foi terça-feira, ou segunda-feira... Tava eu e outro moleque, fomos lá, foi o maior risco, subimos no lugar alto, passava viatura, podia ver você. Você fica com medo, mas o medo não abala. Eu gosto de passar medo assim, mas tipo uma aventura. Mas a gente conseguiu pichar, ninguém catou a gente.

É ter ibope, adrenalina, viver o perigo. Pichar é vontade de muitos e coragem de poucos.

Como assinala Erikson (1972), o relacionamento dos adolescentes entre si e com a sociedade configura-se num palco para a expressão e experimentação de reações emocionais relacionadas a identidade grupal. Aqui é fundamental o reconhecimento mútuo do que é realizado, expresso, sentido e a afirmação reiterada da identidade individual e social.

Todos os sujeitos afirmaram que a sociedade os percebia de maneira depreciativa, como vândalos, "vagabundos" e marginais. Isso indica uma relação de atrito e conflito entre sociedade e esses grupos de jovens. Essa relação intensifica o sectarismo já existente nos grupos. Intensifica-se assim a fricção presente no contato sociedade/adolescente, e, segundo Oliveira (1976), isso pode acrescentar significação ideologicamente negativa, desvalorizada, à construção da identidade desses jovens:

Eles vê como um vandalismo, fala isso daí, vandalismo, mas não é nada disso. Tudo para eles querem condenar, a população quer condenar nóis, pensa que isso é coisa errada. Mas eu não acho uma coisa errada, eles acham isso mas eu não acho. Pessoas que querem condenar sem saber, não tem futuro, não sabe se os outros tem problema ou coisa assim.

Eles não sabem o que é pichar, condenar é fácil. 
A sociedade não vê os pichadores, mas criticam mesmo assim, porcausa da pichação que ela vê.

Como vândalos, marginais, às vezes até como maconheiro, sei lá, a maioria pensa assim.

Os adolescentes pesquisados também expressaram percepções particularmente depreciativas das autoridades legais, como polícia e governo. Os representantes da lei e da ordem são percebidos como instituições sociais violentas e corruptas, isto é, claramente sem legitimidade para representar a justiça e a lei. Os dados desse trabalho indicam que a lei é compreendida como passível de um marcante relativismo.

Sendo assim, a ausência de crítica sobre suas práticas, aliadas ao inconformismo com aquilo que as autoridades, e de forma mais abrangente, a sociedade, assinalam como positivo, proporciona ao adolescente uma paradoxal reação, conformando e organizando o que Erikson (1972) denominou identidade negativa:

O piche sai para quem é pichador mesmo. A gente não vai fazer mal para ninguém. Às vezes os caras ficam atacados: picharam meu muro, mas se eles pensarem, não tem como impedir que façam isso.

Não obedecer é algo eletrizante. Fazendo o que não pode, deixa você uma pessoa vitoriosa, quebrando a lei.

Obedecer é algo insignificante, só fazer o que pode não tem graça.

Tem umas leis que não tem nada a ver de obedecer, elas falam que não podem mexer em coisas do governo, mas se não tiver funcionando nóis não vai mexer? Se tem uma coisa minha eu cuido, mas o governo não cuidou daquele prédio que pichamos, tava abandonado, tem terreno do CDHU que a gente invadiu que a polícia foi lá tirar a gente, não pode invadir, mas tá errado.

Depende né. Dependendo da lei eu obedeço e dependendo da lei eu não obedeço não. Por que, tipo, meu pai não quer que eu ande com moleque que foi preso, e o juiz também fala isso, mas eu tô andando. É uma lei normal, mas eu acho que é uma frescura.

Mas não sei não se tem lei que eu obedeço, por que hoje em dia, é tudo crime para eles... Polícia, delegado. 
Para Erikson (1972), as reações de repúdio e desqualificação do meio proporcionam a construção de formas identitárias possíveis de serem assumidas, ainda que reprovadas socialmente. Tais identidades negativas são revestidas de notoriedade, principalmente pelo incômodo e visibilidade que implicam, como ocorre com os pichadores. A reprovação social passa, então, a ser o ponto de partida para uma nova identidade assumida, uma identidade viável para a quem restaria um vazio identitário talvez insuportável.

Tais aspectos se evidenciam melhor quando se notou ocorrer identificações com o grupo étnico negro, o mais marginalizado, discriminado. Um número expressivo de adolescentes, percebidos como brancos pelo entrevistador, considerava-se negro, ou seja, optava por ser incluído no grupo étnico mais discriminado na sociedade brasileira. Obviamente, além desse aspecto de identificar-se com o "discriminado", há também a identificação da cultura negra veiculada pelo hip hop, numa retomada de uma africanidade positiva reconstituída.

Finalmente, é importante observar que a formação da identidade nesse contexto e processo sociocultural é produto e resulta numa crise psicossocial mais intensa, que evolui para comportamentos francamente delinqüentes. Vários dos pichadores estudados foram também praticantes de atos infracionais graves. Isso certamente tem a ver com a forma como se obteve a amostra do estudo, mas, de todo modo, inclui relações entre a transgressão menor da pichação e formas bem mais sérias de transgressão e crime.

\section{Conclusão}

Através da prática da pichação e da organização grupal dos jovens inseridos nessa atividade, pôde-se observar um dinâmico processo identitário, assim como a apropriação de ideologias que regem a sociedade capitalista, como os sistemas de comunicação e marketing e a competitividade mercadológica.

Dessa forma, paradoxalmente, os adolescentes, ao criarem uma cultura aparentemente alheia ao universo dos adultos, sectária a ele, ou seja, ao mercado e suas formas de organização, ao mesmo tempo constituiu uma subcultura com valores e propósitos semelhantes. A busca de marcas de destaque, a maior capacidade de produção destas e a visibilidade social, constantes em suas atividades, expressam bem tal apropriação.

Por outro lado, os jovens pichadores também se identificaram com os aspectos transgressores dessa prática; reconhecem-se como desqualificados pela sociedade. Marcados por certa negatividade, identificam-se com um papel rejeitado, que, apesar de marcadamente pejorativo, é acessível a eles. 
É possível que a crise inerente a esse peculiar processo de busca e construção de identidade possa, em situações extremas, resultar em desenvolvimentos delinqüentes.

\title{
Young graffiter: Psico-social profile. Identity and Motivation
}

\begin{abstract}
This study investigated the psycho-social profile of adolescents involved in the practice of illegal graffiti ("pichação"). It refers to a subculture linked to hip hop movement, present in medium and large cities in Brazil. The objective of this study was to describe the cultural profile of adolescents involved in "pichação" and issues related to identity and motivation processes of these adolescents. In doing so, 32 subjects answered an inventory which approached psychological and sociocultural aspects of this kind of graffiti. These adolescents were all males, with a mean age of $17.2 \pm 2.6$ years, living in outskirt areas of large cities. The interviews showed that such form of graffiti is related to marked identity processes and describes how such adolescents interact with their peers and leaders, as well as how they represent and deal with social general values and laws. Moreover the main motivations for those youths to participate in this transgressor activity were presented.Conclusion:The youths involved with "pichação" use such activity as a way to establish their identities and to confront the general society. These aspects were analyzed focusing on the identity building and its crises in the adolescence, according to Erik Erikson contributions. Moreover the implication of the contemporary market ideologies of dominant society in this adolescent subculture was analyzed in this process.
\end{abstract}

Keywords: Adolescents. Identity. Graffiti (art).

\section{Jeunes qui font du Graffitti: Profil psycossocial, identité e motivation}

Résumé: Introduction : Cette étude a investigué le profil psycossocial des adolescents qui sont dans la pratique du graffitti urbain. C'est une sous-culture liée au mouvement hip-hop, présent dans les moyennes et grandes villes brésiliennes. Elle a eu comme objectif décrire les processus de l'identité et de la motivation de ces adolescents. De cette façon 32 individus ont répondu a un inventaire qui a touché les aspects psycologiques et socio-culturels du graffitti. Les Jeunes qui font du graffitti étaient tous du genre masculin, avec un âge moyennant entre 17,2 plus ou moins 2,6 ans et habitant la périphérie des grandes villes. Les interviews ont montré que le graffiti est lié a des processus de l'identité très touchants pour ses auteurs, ainsi comme ça a montré aussi la manière comment ils se relationnent avec leurs semblants 
et leaders et comment ils se relationnent avec la societé en général et la loi. Conclusion: Les jeunes liés au graffitti s'utilisent de cette pratique comme une façon de définir ses identités et confronter la société. Le graffitti a été analysé en accord avec les concepts d'Erik Erikson relationnés avec la crise d'identité dans l'adolescence. L'implication des idéologies de marketing de la société générale et dominante a été observée, articuleé avec le processus du graffitti.

Mots-clés: Adolescents. Identités. Graffitti (art).

\section{Grafiteros jóvenes: Perfil psicosocial, identidad y motivación}

Resumen: Este estudio investigó el perfil sicosocial de los adolescentes implicados con la práctica de la pintada urbana. Es una subcultura vinculada al movimiento presente en las medias y grandes ciudades brasileñas. Su objetivo fue describir los procesos de identidad y de motivación de estos adolescentes. De esa manera, 32 sujetos contestaron a un inventario sobre los aspectos sicológicos y socioculturales de la pintada. Los jóvenes pintadores eran todos del sexo masculino, de edad media $17.2 \pm 2.6$ años y habitantes de la periferia de grandes ciudades. Las entrevistas demostraron que la pintada se relaciona a importantes procesos de identidad para sus autores, y también como indicaron como se relacionan con sus pares y líderes y con la sociedad general y la ley. Conclusión: los jóvenes implicados con la pintada se utilizan de eso como forma para demarcar sus identidades y para confrontar la sociedad. Se analizó la pintada según los conceptos de Erik Erikson con relación a la crisis de identidad en la adolescencia. Se observó la implicación de las ideologías de marketing de la sociedad general y dominante, articulada con el proceso de la pintada.

Palabras-clave: Adolescente. Identidad. Grafitte (arte).

\section{Referências}

Erikson, E. H. (1972). Identidade, juventude e crise. Rio de Janeiro: Zahar.

Hall, S. (2003). A identidade cultural na pós-modernidade. Rio de Janeiro: DP\&A.

Lara, A. H. (1996). Grafite - arte urbana em movimento. Dissertação de Mestrado, Instituto de Comunicação e Artes, Universidade de São Paulo, São Paulo.

Kett, J. F. (1993). Descubrimento e invención de la adolescência em la história. Journal of Adolescent Health, 14, 664-672.

Magro, V. M. M. (2002). Adolescentes como autores de si próprios: cotidiano, educação e o hip hop. Cadernos Cedes, 22, 63-75. 
Minayo, M. C. S. (2004). O desafio do conhecimento: pesquisa qualitativa em saúde. São Paulo: HUCITEC.

Silveira, N. E. (1991). Superfícies alteradas: uma categoria dos grafites da cidade de São Paulo. Dissertação de Mestrado, Instituto de Filosofia e Ciências Humanas, Universidade Estadual de Campinas, Campinas, SP.

Oliveira R. C. (1976). Um conceito antropológico de identidade. In R. C. Oliveira, Identidade, etnia e estrutura social (pp. 33-50). São Paulo: Pioneira.

Alex de Toledo Ceará, Psicólogo clínico, membro do Laboratório de Saúde Mental e Cultura e mestrando do Departamento de Psicologia Médica ePsiquiatria,Universidade Estadual de Campinas. Rua Doutor Francisco de Arruda Roso, 362 - Vila Itália - CEP 13034-490 - Campinas - SP. Endereço eletrônico: detoledoceara@itelefonica.com.br

Paulo Dalgalarrondo, Psiquiatra, Prof. Livre-docente do Departamento de Psicologia Médica e Psiquiatria, Universidade Estadual de Campinas. Endereço eletrônico: pdalga@fcm.unicamp.br).

Recebido em: 23/07/2007

Aceito em: 21/03/2008 
